\title{
Reseña de libro
}

\section{El wire de La serie-síntoma}

The Wire. La serie-sintoma | Juan Pablo Duarte | Ediciones Universidad Nacional de Córdoba | 2020

\section{Juan Ernesto Brodsky y Gigliola Foco}

Universidad Nacional de Córdoba, Argentina



Prólogo

Introducción

\section{Capítulo 1. El periódico}

De Los Blairs, los Glasses y Los Kelleys a los templeton y los haynes

Una mentira no es una versión

Los dioses en The Wire

Lo simbólico o la imagen, dos formas de contar un huracán

Hay un asesino en serie en Baltimore

Final y retorno

\section{Capítulo 2. Las calles}

La Esquina

La adicción a los números

La evaluación como código visual

Roland Pryzbylewski

El dinero: de las calles a la política

\section{Capítulo 3. La política}

Omar Little y Maurice Levy Bunny Colvin, "hamsterdam” y la "Ley de gravedad fecal"

Kurt Schmoke y Martin o’Malley

El triunfo de Carcetti: ¿De que mierda habla The Wire?

Lo que no cesa de escribirse en el cuerpo

\section{Capítulo 4. La escuela}

Los chicos del verano

El estudio del Dr. Parenti

Little melvin williams y el infantilismo del tráfico de drogas Marlo Stanfield

Del trabajador al jugador

\section{Capítulo 5. El puerto}

La creencia en el plus de goce

In ponzi we trust

Cuerpos a la deriva

Ziggy: ni trabajador ni traficante

Trabajo y entropía

Conclusiones 
Una firme decisión rompe el hielo y hace de wire en el libro que los invitamos a leer: "para inscribir el síntoma en el contexto del lazo social actual, una serie de televisión podría resultar mejor que las noticias” (p.20).

Esta tesis, devenida en libro, es producto de una rigurosa investigación que llevó adelante el autor en el marco de la Maestría en Teoría Psicoanalítica Lacaniana (MaTPsiL) de la Facultad de Psicología de la Universidad Nacional de Córdoba.

Desde sus primeras páginas, The Wire. La serie-sintoma, traza una geografía singular que comienza por el final. La punta de un hilo del que tirar para sumergirnos en su trama, la que tejen los personajes que testimonian sobre sus modos de mal-vivir la urbe norteamericana: Baltimore. Personajes que, plagados de referencias a la biografía de sus creadores y guionistas, recorren la cartografía de la ciudad.

Caminando entre sus calles, el libro invita al lector, capítulo a capítulo, a dibujar su recorrido en el mapa, impulsado por la introducción del autor que deja la marca de una apuesta: "una lectura psicoanalítica de lo social” (p.21), bajo la brújula de Sigmund Freud y Jacques Lacan, atravesada por la orientación epistémica de Jacques-Allain Miller, y acompañada de las lecturas de Eric Laurent, Gerard Wajcman, Marie-Hélene Brousse, entre otros.

En la época de "El Otro que no existe y sus comités de ética" (Miller, 1996-1997), la decadencia ficcional de la verdad, las verdades cambiantes y las fake newos, este libro invita a preguntarnos cómo inventar otras formas de contar.

El psicoanalista Alejandro Willington (EOL-AMP), miembro del comité de admisión y seguimiento de la MaTPsiL de la Facultad de Psicología (UNC), en el prólogo retoma el concepto de aletósfera que Lacan definió como una atmósfera a la cual era posible conectarse a través de los objetos técnicos, las letosas, y se pregunta qué implicancias tiene su instalación masiva o de The Wire en la escena del mundo contemporáneo. "The Wire, el cableado y su deriva metonímica ineludible, la red, constituye un paradigma global, la red que teje a Baltimore nos alcanza a todos los ciudadanos" (p.13).

En este escenario donde los medios tradicionales de comunicación que alguna vez permitieron descifrar los síntomas de la civilización contemporánea, son "descreídos", las series de televisión se constituyen como "una empresa de pensamiento acerca de las formas que asume el malestar en la cultura en la actualidad" (p. 21). Y es que el wire que atraviesa este libro, permite dar cuenta de que no se trata de cómo la serie refleje, al modo de una radiografía, la veracidad de los hechos, una verdad última que se lograría alcanzar alguna vez. Se apunta en cambio a "su capacidad para localizar elementos que escapan a la verdad y su estructura ficcional” (p.24).

En palabras del autor:

The Wire no pone en escena lo real de la ciudad sino una varidad de sus síntomas. Este neologismo lacaniano marca el rasgo singular de la serie (...). Abordar lo real del síntoma, desde la última enseñanza de Lacan, implica el mismo desafío. No detenerse sólo en escuchar su verdad es condición necesaria para poder leer lo real en él. (p.169)

Lo real del síntoma social, aquello que no cesa de no escribirse, como el eje que atraviesa este libro; sobre una serie que invita a poner la mirada sobre la ciudad, edificada sobre aquello que rechaza, restos caídos fuera del plano que permiten recorrer estas páginas que giran en torno al elemento faltante (Brousse, 2015). Un agujero en el lugar de la metáfora perfecta que explique la urbe americana que no se puede terminar de apresar.

Antes de terminar, un dato más: no es necesario haber visto la serie para poder saborear lo que este libro puede enseñarnos, para subrayarlo y escribir recortes en sus márgenes. Espacios prestados al lector en cada hoja, para poder trazar allí los pasos dados en las calles de este, el Baltimore al cual nos invita su autor: Juan Pablo Duarte. 